\title{
Spatio-temporal effect of urban heat island on cardiovascular diseases
}

\author{
Deng Xin \\ nanjling forestry university \\ Yang Hailin \\ nanjing foresry university \\ Hao Cui \\ Peking University People's Hospital \\ Peng Zhongren \\ University of Florida \\ Liu Wei \\ nanjing forestry university
}

Huanchun Huang ( $\nabla$ huangyanlin2010@163.com )

Nanjing Forestry University https://orcid.org/0000-0002-3330-3732

\section{Research article}

Keywords: Urban heat island, cardiovascular disease, landscape pattern, spatio-temporal feature

Posted Date: November 14th, 2019

DOI: https://doi.org/10.21203/rs.2.17316/v1

License: (c) (i) This work is licensed under a Creative Commons Attribution 4.0 International License.

Read Full License 


\section{RESEARCH ARTICLE}

2

3 Spatio-temporal effect of urban heat island on cardiovascular diseases

4

5

6 7

Huang Huanchun,

${ }^{1}$ School of Landscape Architecture, Nanjing Forestry University, China

E-mail addresses: huangyanlin2010@163.com(Huang Huanchun);

1033052652@qq.com (Deng Xin); 1075746209@qq.com (Yang Hailin);

754655876@qq.com (Hao Cui); 36259471@qq.com (Liu Wei) 


\section{Abstract}

Background: As urbanization progresses, urban built-up areas are expanding, increasing the number of urban heat islands (UHIs) and damaging the cardiovascular health of urban residents. This study aimed to explore the spatio-temporal pattern evolution characteristics of the effect of UHI on cardiovascular diseases (CVDs).

Methods: We analyzed the land surface temperatures (LSTs) retrieved from data from four Landsat remote-sensing images from 1984 to 2017, data on temperature from 95 meteorological stations, and data on CVDs mortality. Based on this, landscape pattern indices were used to analyze the pattern-process-function underlying the effect of UHIs on CVDs.

Results: The effect of UHIs on CVDs increased, thereby increasing the mortality rate by $28.8 \%$ and increasing the affected area by $1683.977 \mathrm{~km}^{2}$ between 1984 and 2017 . The affected areas gradually expanded from the central area of the city, and underwent three evolution stages; the areas highly affected were mainly distributed in the central and southern regions. Patches increased in number, whereas the landscape was fragmented. The area and ratio of high-level patches also showed an upward tendency, increasing the dominance in the overall landscape. The patches of the overall landscape became more complicated in shape, whereas those of high-level ones became less complicated. The degree of concentration of the overall landscape decreased gradually, with the types of landscape patches increasing, reaching a rather even space distribution. 
39 Conclusions: UHIs drastically increase CVDs mortality by increasing temperatures 40 during summer in Beijing, China. As cities expand, the effect of UHIs on CVDs 41 increases in terms of both intensity and area, with overall landscape in uneven 42 distribution, high-level affected areas in point distribution, and low-level ones in 43 large-area concentration. This study, hence, provides theoretical evidence for the 44 prevention and early warning on CVDs.

45

\section{Keywords}

47 Urban heat island, cardiovascular disease, landscape pattern, spatio-temporal feature 


\section{Background}

Currently, $50 \%$ of the world's population lives in cities, and this proportion is expected to rise to $68 \%$ by 2050 [1]. As a result, people migrate into cities, and the built-up area continues to expand, which makes the temperature in urban areas significantly higher than that in the surrounding rural areas [2]. It, thus, severely affects the health of urban residents, especially in terms of the cardiovascular system. Cardiovascular diseases (CVDs), such as coronary heart disease, cerebrovascular disease, peripheral vascular disease, rheumatic heart disease, congenital heart disease, and heart failure, are disorders of the heart and blood vessels. CVDs are the leading cause of death worldwide. In 2016, a total of 17.9 million people died from CVDs, accounting for $31 \%$ of all deaths worldwide. CVDs and their associated deaths are caused by a number of factors [3]. As a result, many epidemiological studies have explored the relationship between air temperature and CVDs [4].

The excess mortality that occurs during summers is usually attributed to an increased prevalence of CVDs $[5,6]$. The relationship between temperature and mortality due to CVDs is usually depicted as U-, V-, or J-shaped, indicating that the mortality rate increases gradually when temperature exceeds the threshold [7]. Threshold temperature, a critical standard for identifying the extent of urban heat island (UHI) damage on health [8], can help explore the spatio-temporal pattern of the effect of UHI on CVDs. studies have revealed threshold temperatures. Previous studies, however, mainly focused on quantifying the epidemiologic effect of environmental temperature on CVDs, which was unable to explain the mechanism 
underlying the spatio-temporal interaction between them.

Recently, some scholars have used landscape pattern indices to analyze the spatio-temporal evolution of heat island landscapes $[9,10]$, but not the effect of the spatio-temporal response mechanism of UHI on human health. In addition, the landscape pattern is related to multiple diseases $[11,12]$. study proved that a positive correlation exists between regional landscape fragmentation and temperature and the incidence rate of Lyme disease [13]. These indicate that the landscape pattern is related to human health, but the focus is always on landscape patterns and the mechanisms by which landscape structures affect disease, and not exploring landscape-pattern-process of the effect of UHI on human health. Thus, this study used the landscape pattern index to study the spatio-temporal evolution of the effect of UHI on CVDs and reveal the pattern-process-function and influencing mechanism of UHI on CVDs.

From 1984 to 2018, the UHI effect has become more serious, and the incidence of heat wave has increased significantly, particularly in world-class mega-cities like Beijing. This has led to a sharp increase in mortality due to CVDs. However, the effects of spatio-temporal characteristics of UHI on CVDs mortality remain unclear. This study used data from Landsat remote-sensing, meteorological stations, and maps, to analyze the spatio-temporal evolution of the landscape pattern of UHI on CVDs using data analysis software, such as ENVI, ArcGIS, and Fragstats. Ultimately, this study should provide decision-making evidence for healthy urban planning and optimization of ecological environments, thereby reducing the heat exposure risk of 
patients with CVDs.

\section{Methods}

\section{Data sources and preprocessing}

Data sources

Data on temperature were retrieved from Landsat satellite images and meteorological stations. The remote-sensing images were taken on August 16 1984, June 17 1991, August 2 1999, and July 10 2017. When the satellite was present in Chinese territory, atmospheric visibility was sound without cloud covering the study area, and the average wind speed two days before image collection was below $2.3 \mathrm{~m} / \mathrm{s}$ without any

Diseases, 10th revision (ICD-10). Data on CVD mortality in Beijing were obtained from the analysis of the Chinese Center for Disease Control and Prevention [14].

Data preprocessing

First, a radiometric calibration was performed according to NASA's Landsat handbook [15], and digital number values were converted into the corresponding thermal radiation intensity $L(\lambda)$ values. The images were calibrated to $0.5 \mathrm{~m}$ resolution, and any error was controlled within 1 pixel. Next, data were resampled to 
Last, a database was established using the ArcGIS software to extract remote-sensing data in different periods for analysis.

\section{Research methods}

Air temperature retrieval

Land surface temperature (LST) and near-surface air temperature (NSAT) are two important parameters for studying the interaction mechanisms of UHI; a good correlation can be established between both. Concurrently, studies prove that LST and land surface index by Thematic Mapper (TM) retrieved [16] can serve as valid data to study urban thermal health [17].

Atmospheric calibration was applied in this study. First, radiometric calibration was performed according to the NASA manual (landsat.usgs.gov/documents) to transform the digital number into relevant heat radiation intensity. Then, the normalized difference vegetation index (NDVI) and vegetation coverage were calculated. Next, the calculation method for emissivity proposed by Qin et al. was used to obtain land surface emissivity via NDVI and vegetation coverage [18]. Finally, LST was calculated using the following $\left(\mathrm{T}_{\mathrm{L}}\right)$ formula:

$$
T_{L}=\frac{T}{1+(\lambda T / \rho) \ln \varepsilon} \quad 273.15
$$

where $\lambda$ is the central wavelength of TM6 band $(11.5 \mu \mathrm{m})$,
$\rho=h \times \frac{c}{\sigma}=1.438 \times 10^{-2} \mathrm{~K} \quad$ (where $\quad$ Stefan-Boltzmann's
$\sigma=1.38 \times 10^{-23} J / K$, Planck's constant $h=6.626 \times 10^{-34} J_{S}$, and speed of light, 
$\left.136 \quad c=2.998 \times \frac{10^{8} m}{s}\right)$.

Data on LST retrieval were collected from the tests in 95 surface meteorological stations between July 10 and August 22 2015, based on which the temperature regression formula was established. The regression formula of land surface temperature was established by using the land surface temperature inversion data of 95 weather stations from July 10 to August 22, 2015. These 95 surface meteorological stations are prioritized from 360 surface meteorological stations. First, the coefficient among NDVI, normalized difference water index (NDWI), architectural composition, and daily average temperature were calculated in various scales. The results revealed that daily average temperature was closely related to NDVI at $160 \mathrm{~m}$ and LST at 300 m resolution. Next, software, such as SPSS and MATLAB, were used for curvilinear regression, indicating that sound regression results had a linear polynomial relationship, and that regression formulas enhance the robustness of sound. The coefficient of determination $\left(R^{2}\right)$ was 0.95 , the root-mean-square error was 0.13 , and the regression formula was as follows:

Relationship between increased UHI and increasing CVD mortality

155 UHI controls urban temperature, which leads to increased morbidity and mortality rates due to CVDs, but the effect of high temperature on such mortality still faces a 
to 2013 in Jinan, China, Li estimated the thermal threshold of CVD mortality using observation and prospective analysis. The results showed that the maximum, average, and minimum threshold temperatures in Jinan were $32^{\circ} \mathrm{C}, 28^{\circ} \mathrm{C}$, and $24^{\circ} \mathrm{C}$, with $4.1 \%$, $7.2 \%$, and $6.6 \%$ increases in mortality rates, respectively, per unit rise in temperature [14] (Fig. 1). This is because Beijing and Jinan belong to the temperate monsoon and the difference in longitude is small. They both belong to megacities on the same longitude. Therefore, based on the relationship between daily mean temperature and CVD mortality assessed, this study explores the spatio-temporal evolution of the effect of UHI on CVDs.

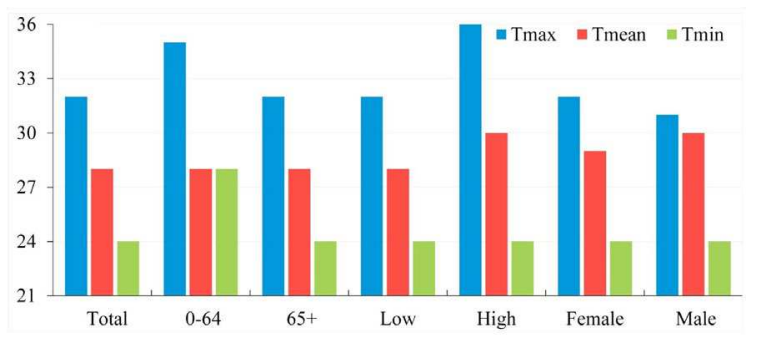

Fig. 1. Heat thresholds of Tmax/Tmean/Tmin [14]

Grading of the effect of UHI on CVDs

Modern medical studies have revealed that environmental temperature is closely related to the physiological activities of the human body. The coziest environmental temperature is $20-28^{\circ} \mathrm{C}$. When the body temperature exceeds $28^{\circ} \mathrm{C}$, our blood vessels dilate, transporting more blood to the skin surface, thereby increasing the temperature of the skin and making us feel uncomfortable. Once the temperature exceeds $30^{\circ} \mathrm{C}$, some sweat glands are activated to dissipate heat in the form of perspiration, thereby dilating the skin vessels and re-allocating the blood. Concurrently, more blood enters 
and leaves the heart, increasing the cardiac load [21,22]. When the temperature increases beyond $32{ }^{\circ} \mathrm{C}$, it reaches the maximum threshold temperature for CVD mortality in Jinan [14].

All in all, according to the threshold temperature and the physiological response of the human body to high temperature, this study was based on the threshold temperature at which UHI affected CVDs in Beijing with the daily average temperature of $28^{\circ} \mathrm{C}$, and the UHI intensity was $2^{\circ} \mathrm{C}$. With each unit increase in threshold temperature, the mortality rate increased by $7.2 \%$. Therefore, we classified the effect of UHI on CVD mortality into five levels as shown in Table 1. Level 1 implied that UHI had a lower effect on CVD mortality. Levels 2, 3, 4, and 5 represent medium, high, and very high effects.

Table 1. Grading of the effect of UHI on CVDs mortality

\begin{tabular}{|c|c|c|c|c|}
\hline Level & $\begin{array}{l}\text { Temperature } \\
\quad\left({ }^{\circ} \mathrm{C}\right)\end{array}$ & $\begin{array}{c}\text { UHI } \\
\text { intensity } \\
\left({ }^{\circ} \mathrm{C}\right)\end{array}$ & $\begin{array}{l}\text { Increase } \\
\text { in } \\
\text { mortality } \\
\text { rate }(\%)\end{array}$ & Remark \\
\hline Level 1 & $28-29$ & $2.7-3.7$ & $0-7.2$ & $\begin{array}{l}\text { Humans starts to feel a little } \\
\text { uncomfortable }\end{array}$ \\
\hline Level 2 & $29-30$ & $3.7-4.7$ & $7.2-14.4$ & $\begin{array}{l}\text { Humans feel uncomfortable, } \\
\text { with slight sweating }\end{array}$ \\
\hline Level 3 & $30-31$ & $4.7-5.7$ & $14.4-21.6$ & $\begin{array}{l}\text { Humans feel very } \\
\text { uncomfortable, with much } \\
\text { sweating }\end{array}$ \\
\hline Level 4 & $31-32$ & $5.7-6.7$ & $21.6-28.8$ & $\begin{array}{l}\text { Cardiovascular system starts to } \\
\text { be affected, with increased } \\
\text { cardiac output, aggravated } \\
\text { cardiac load }\end{array}$ \\
\hline Level 5 & $32+$ & $6.7+$ & $28.8-36$ & $\begin{array}{l}\text { Temperature reaches the critical } \\
\text { value of daily maximum } \\
\text { temperature for CVD mortality }\end{array}$ \\
\hline
\end{tabular}


193 Methods of evaluation of landscape pattern indices

194 Landscape pattern refers to the permutation of landscape patches of various sizes in 195 the landscape space [23]. Quantitative analysis could be performed on changes and 196 differentiation characteristics of landscape patterns by introducing landscape pattern 197 indices. The indices include three levels: patch, class, and landscape. This study, 198 therefore, started from class and landscape levels and selected 10 landscape pattern 199 indices to quantitatively describe the landscape pattern characteristics that yield an 200 effect on CVDs. The indices selected include class level - PD, cohesion 201 (COHESION), and landscape shape index (LSI); and landscape level — main patch 202 area (AREA_MN), shape index (SHAPE_AM), aggregation index (AI), contagion 203 index (CONTAG), and Shannon diversity index (SHDI) [24]. Indices of the class 204 level demonstrate the quantity and structure of patch types at all levels, whereas those 205 of the landscape level reflect the global feature of the study area.

Survey of Research Areas

Beijing $\left(39.56^{\circ} \mathrm{N}, 116.20^{\circ} \mathrm{E}\right)$, one of the first-tier cities in the world, is the center for 209 politics, economy, and culture of China, belonging to the semi-humid continental 210 monsoon of the north temperate zone, which is hot and humid during summer. At the 211 end of 2018, the permanent population in Beijing reached 21.542 million, the rate of urbanization was $86.5 \%$, and the gross domestic product exceeded 3 trillion Yuan. 

arose, yielding a negative impact on both the physiological and psychological health of urban residents. Against the backdrop of economic globalization, the urban sprawl in Beijing became more probable as UHI became more serious [25]; thus, high temperatures engulfed Beijing for 22 days in 2017, gaining worldwide attention. It is therefore of significance to study UHI in Beijing (Fig. 2).

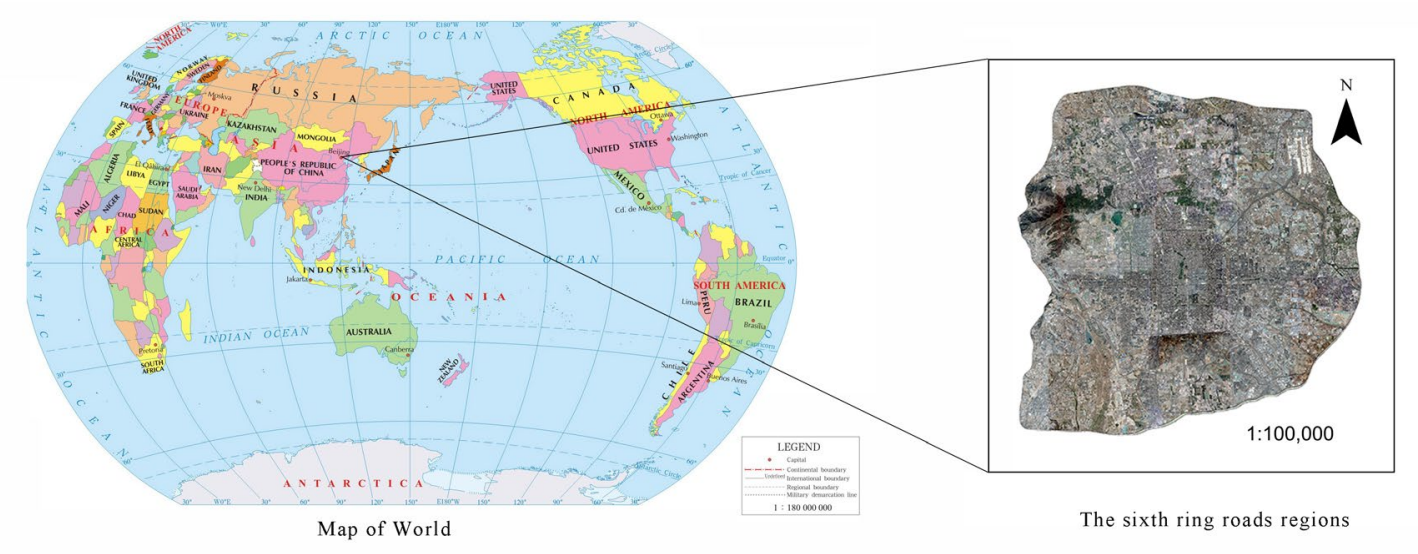

\section{Results}

\section{Spatial characteristics of the effect of UHI on CVDs}

Fig. 2. Outline of the study area

During 1984-2017, the effect of UHI on CVDs increased from level 2 to level 4, resulting in a $28.8 \%$ increase in mortality rate and a $1683.977 \mathrm{~km}^{2}$ increase in the affected area. Affected areas showed a trend of expansion from the central area outwards in spatial distribution, showing an obvious spatio-temporal correlation with the process of urban sprawl. The highly affected areas were chiefly concentrated in the central and southern parts; the air temperature in the northern mountainous area was relatively low, making it easier to build up high pressure. Meanwhile, air 
temperature in the urban area was relatively high, resulting in low pressure and triggering cold air flow from the northern mountainous area to the urban area.

As illustrated in Fig. 3, levels 1 and 2 affected areas only emerged within the sixth ring road of Beijing during 1984-1999; no highly affected areas were spotted. In detail, level 1 affected areas were mainly distributed in the urban center, gradually expanding to the southern suburbs. Level 2 affected areas were smaller and scattered in the south. In 2017, level 1 patches shrunk drastically, whereas level 2 patches expanded drastically and transformed from scattered points to relatively concentrated plates and facets. Meanwhile, some low-level patches in business centers transformed into high-level patches. Such drastic changes in the spatial distribution of all affected areas were triggered by the fact that in the past two decades, Beijing city (particularly the urban area) developed rapidly as businesses increased, resulting in a series of environmental problems and affecting the cardiovascular health of residents. 


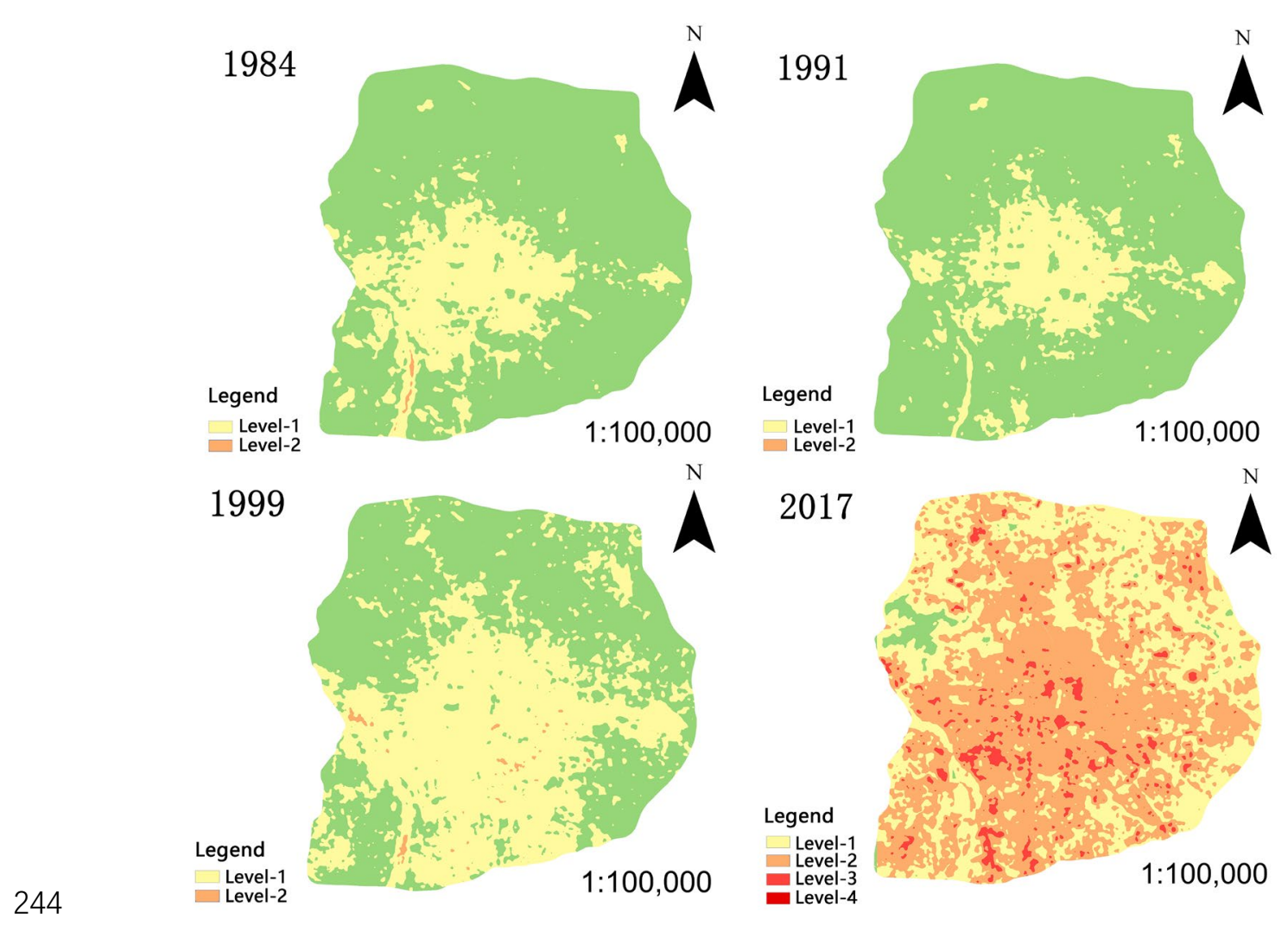

Fig. 3. Distribution of affected areas during 1984-2017

Changes in class level

249 The changes in PD between 1984 and 2017 are shown in Table 2. In general, PD

250 increased in a fluctuating manner, indicating that affected areas at all levels showed a

251 tremendous trend of fragmentation and separation. In detail, during 1984-1991, levels

2521 and 2 affected areas increased slowly yet stably due to the rather slow pace of urban

253 construction. During 1999-2017, however, levels 1 and 2 affected areas decreased,

254 whereas levels 3 and 4 affected areas emerged. This was mainly because urban sprawl

255 tremendously increased the temperature in urban centers, exacerbated the

256 cardiovascular health of residents, and led to a gradual transformation of level 1 
affected areas into high-level ones.

258

Table 2. Changes in PD during 1992-2018

\begin{tabular}{ccccc}
\hline & 1984 & 1991 & 1999 & 2017 \\
\hline Level 1 & 0.0692 & 0.078 & 0.1159 & 0.0957 \\
Level 2 & 0.0022 & 0.0022 & 0.0159 & 0.071 \\
Level 3 & 0 & 0 & 0 & 0.1275 \\
Level 4 & 0 & 0 & 0 & 0.0004 \\
\hline
\end{tabular}

259 generally, indicating that affected areas at all levels became more complicated in

262 shape. During 1999-2017, the LSI of levels 1 and 2 affected areas increased rapidly;

263 the fast urbanization triggered the expansion of urban shape and added many patches

264 of independent built-up areas. Meanwhile, levels 3 and 4 affected areas were less

265 complicated because high-level affected areas were mainly concentrated in business

266 centers and resident areas where patch shapes tended to be simpler.

Table 3. Changes in LSI during 1992-2018

\begin{tabular}{ccccc}
\hline & 1984 & 1991 & 1999 & 2017 \\
\hline Level 1 & 12.1617 & 13.1989 & 14.5865 & 23.0332 \\
Level 2 & 3.5948 & 2.3 & 6.8798 & 22.6149 \\
Level 3 & 0 & 0 & 0 & 18.6593 \\
Level 4 & 0 & 0 & 0 & 1.0714 \\
\hline
\end{tabular}


COHESION of level 1 affected areas was stable, indicating that patches shared sound

271 interconnectivity with relatively concentrated distribution, which was not beneficial to

272 the rapid thermal dissipation inside patches. The elevated air temperature increased 273 the CVD mortality rate. COHESION of level 2 affected areas fluctuated due to urban 274 renovation. In addition, COHESION of levels 3 and 4 affected areas were relatively 275 low with weaker interconnectivity; patches were small in area and distributed in 276 points.

Table 4. Changes in COHESION during 1992-2018

\begin{tabular}{ccccc}
\hline & 1984 & 1991 & 1999 & 2017 \\
\hline Level 1 & 99.8218 & 99.6738 & 99.8833 & 99.7612 \\
Level 2 & 97.0525 & 90.0021 & 96.2389 & 99.9433 \\
Level 3 & 0 & 0 & 0 & 96.9449 \\
Level 4 & 0 & 0 & 0 & 84.978 \\
\hline
\end{tabular}

279 Changes in landscape level

280 The changes in PD and AREA_MN between 1984 and 2017 are shown in Fig. 4. PD 281 increased generally, whereas AREA_MN index decreased, indicating that the 282 landscape distribution was heading towards fragmentation. During 1984-1991, PD 283 and AREA_MN nearly remained unchanged due to the rather slow pace of urban 284 construction. 


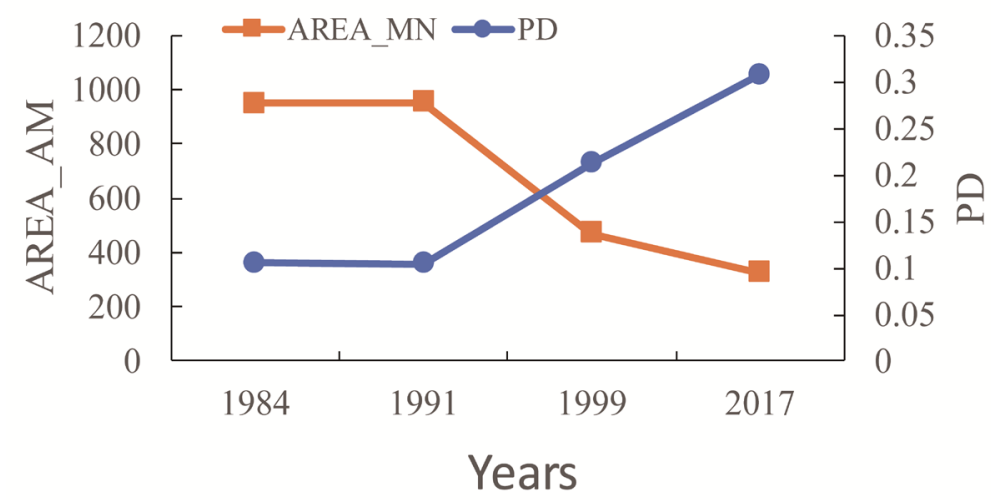

Fig. 4. Changes in PD and AREA_MN during 1984-2017

The changes in SHAPE_AM between 1984 and 2017 are shown in Fig. 5.

SHAPE_AM increased generally, indicating that the shape of all affected areas became irregular and that the effect of UHI on CVDs became much more complicated

291 in spatial distribution. During 1984-1999, SHAPE_AM increased steadily due to the 292 rather slow pace of urban development and that urban form was quite stable. However, 293 SHAPE_AM increased rapidly during 1999-2017; rapid urban development and 294 three-dimensional expansion resulted in many new business centers and development projects.

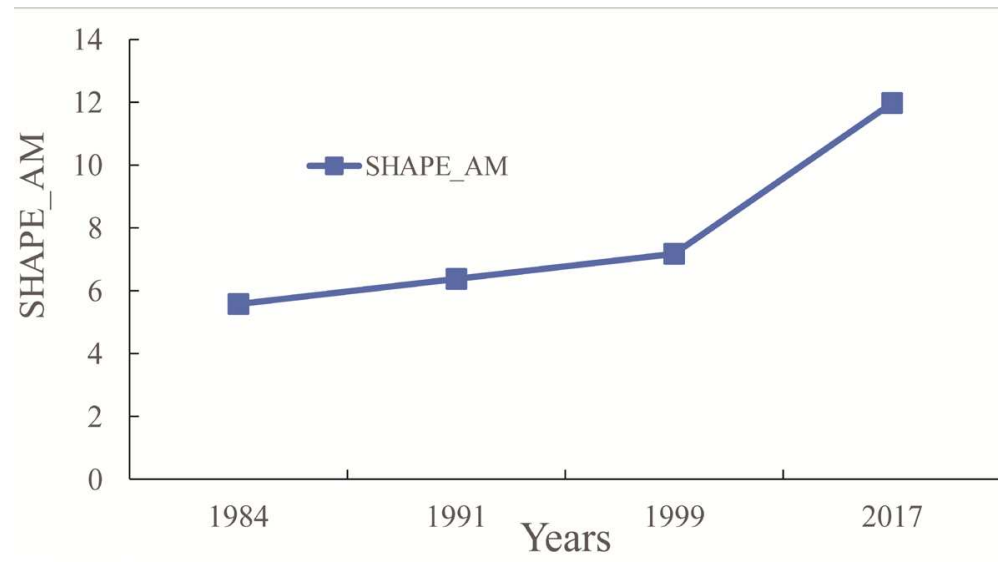



decreased in general, indicating that the overall landscape was distributed in a scattered manner, and that the landscape was highly fragmented. Patch adjacency was much more decentralized, and the interconnectivity within the affected areas was weak. During 1984-2017, SHDI, an index that describes the diversity of patch, increased generally, indicating that urban built-up areas expanded towards suburbs. In addition, the increased UHI yielded a greater impact on many types of landscape patches with a higher degree of fragmentation. During 1984-1991, SHDI decreased slightly; the effect of UHI on CVD mortality was not very obvious as urbanization slowed down, so that the expansion of level 2 areas dropped in scale, resulting in reduced diversity of patch types.
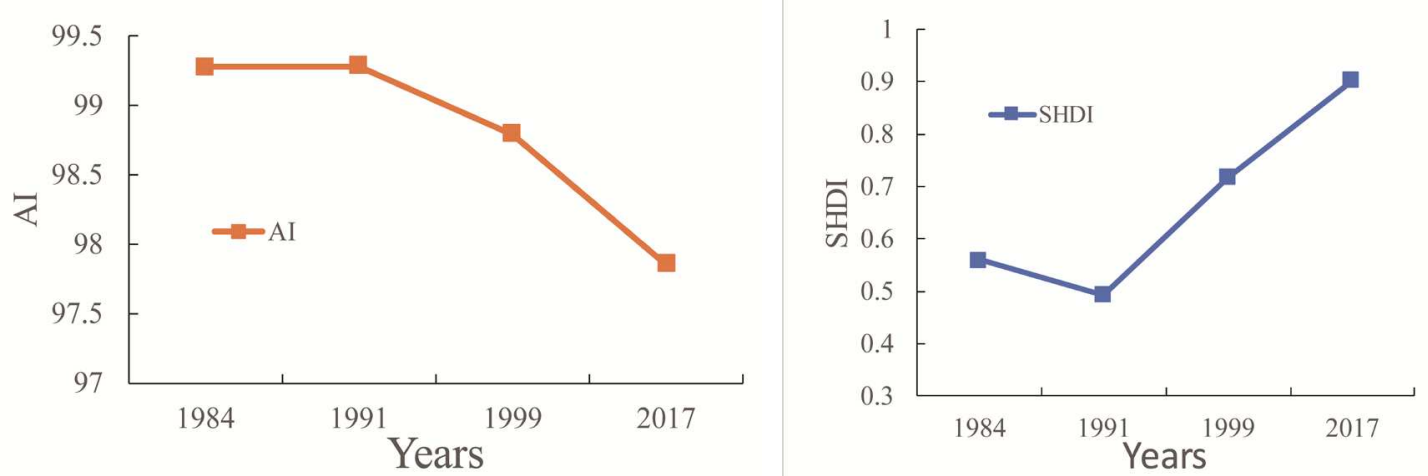

Fig. 6. Changes in AI and SHDI during 1984-2017

\section{Response mechanism of UHI on CVDs}

High temperature increases CVD mortality by affecting cardiopulmonary functions, including the blood pressure, blood viscosity, serum cholesterol, and heart rate $[26,27]$. First, elevated air temperatures increase the heart rate and myocardial oxygen consumption in the human body. Meanwhile blood is transported faster from organs to 
the skin surface, creating higher pressure on the heart and lungs [28], further increasing the incidence rate of CVDs. In addition, the amount of perspiration from the human body increases. Conversely, this leads to a massive loss of sodium, $\mathrm{pH}$

321 imbalance, and electrolyte disturbance in cells, further resulting in arrhythmia and malfunction of the circulation system, which eventually induces CVDs [29]. Conversely, blood viscosity and cholesterol level increase, but the effective 324 circulating volume decreases, triggering insufficient blood supply through the coronary arteries and even myocardial infarction [30]. Last, inappropriate use of air conditioning also indirectly increases the CVD mortality rate. In detail, when the indoor-outdoor temperature difference is $>8^{\circ} \mathrm{C}$, it becomes difficult for the human body to adjust to the current temperature within a short time. Such drastic differences lead to continuous constriction or dilatation of blood vessels, resulting in a disturbance of blood circulation and further triggering myocardial infarction or stroke. increasing temperature during summer. Under high temperatures, the body functions of elderly people decline and the amount and rate of perspiration of each gland reduces; thus, loss of heat in turn increases the accumulated heat inside the body, 335 exacerbating the tension on the cardiovascular system. Under long-term thermal 336 stimulation, constant perspiration causes the blood plasma volume to decrease 337 dramatically; however, blood viscosity increases, thereby increasing the CVD 338 mortality rate [8]. Moreover, some drugs usually taken by elderly people disturb the normal perspiration or other processes that adjust body temperature, thereby 
exacerbating the CVD mortality rate.

Elevated temperature during the summer caused by UHI is usually accompanied by increased air pollution, which yields a severe impact on CVDs. Atmospheric particulates triggered by heat waves increase in density, and increase the blood viscosity, pressure, and heart rate variability, thereby triggering diseases such as acute myocardial infarction [31]. Moreover, the increase in ozone density caused by high temperature exacerbates the CVD mortality. Some studies have proven that with every $10 \mu \mathrm{g} \cdot \mathrm{m}^{-3}$ rise in ozone levels in the air, the CVD mortality rate among the Chinese population increases by $0.448 \%$ [32]. This is because the increased ozone density triggers inflammation, oxidative stress, and myocardial cell damage, and affects vessel structure and the transcription mechanism, lipid metabolism, and cardiovascular autonomic regulation [33].

\section{Discussion}

Our findings showed that UHIs have a significant effect on CVDs mortality by increasing ambient temperature in summer. Previous studies have proven that high temperatures are significantly correlated with CVDs mortality [34]. Baaghideh and

$4.27 \%$ per unit rise in maximum air temperature ( $95 \%$ confidence interval, $0.91-7.00)$

360 [35]. This is consistent with our study. And related studies have explained the reasons. 
cells in coronary arteries, increased the permeability of the tunica intima, reduced the superoxide dismutase activity of heart tissues, and finally increased the lipoprotein levels in oxygenated blood. As a result, high levels of cholesterol penetrated and were deposited on the tunica intima, causing atherosclerosis and exacerbating coronary heart disease [36].

Our findings revealed that the UHIs effect on CVDs have typical spatial and temporal characteristics. And the affected areas gradually expand to suburbs, mainly in central and southern urban areas. Previous studies have reported that high temperature clusters of heat wave in Beijing are mainly within the second ring road of Beijing, whereas heat wave risk obviously decreases from the second to sixth ring 372 roads [37]. The spatial distribution of high temperature heat waves has certain 373 similarities with our study, which further supports the impact of UHIs effect on CVDs. 374 Meanwhile, the findings of this study demonstrated that the effect of UHI on CVDs 375 evolves through three stages, namely concentric ring growth, axis expansion, and 376 regional filling (Fig. 7).

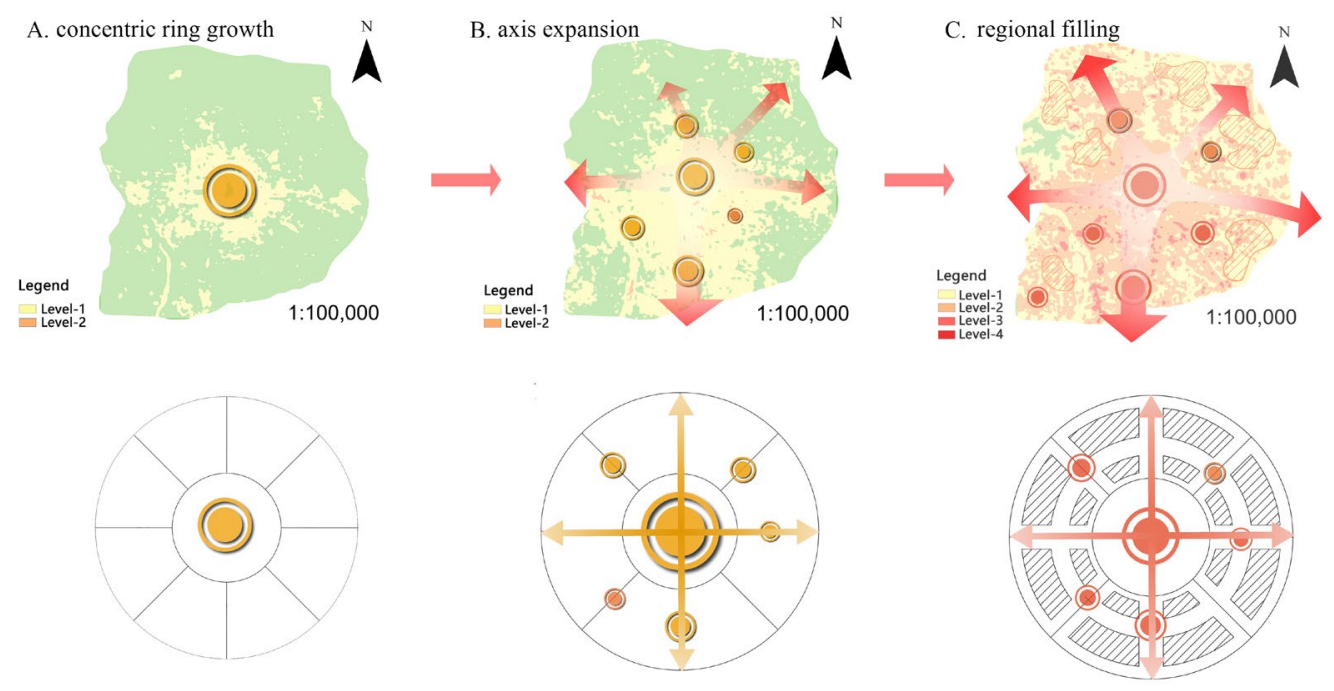


We also found that UHIs have a typical landscape pattern process for the effect on CVDs. The overall landscape is distributed in a scattered manner. Similar studies revealed that the incidence of vector-borne Lyme disease is significantly related to the degree of regional landscape fragmentation and temperature [14]. Therefore, it is feasible to use the landscape pattern index method to study the effect of UHI on CVDs. This study provides a theoretical basis for the optimization of urban spatial structure and green space system. In the process of rapid urban development, according to the law of coordinated changes in environment and residents' health, the heat hazard sensitive space of the heat island is pre-judged, and then the countermeasures for the controllable and adjusted planning factors are taken. regression model; this study subtracted the effect of the intercept during air temperature retrieval to better reflect the intensity of UHI, resulting in overall underestimation of the effect on CVDs mortality. Finally, given the impact that etc., which may affect the temporal and spatial evolution of CVDs in UHI. weather and climate have on satellite images, this study used the two images to explore the spatio-temporal effect of UHI on CVDs during 1999-2017. The temperature-mortality relationship in this study cites the results of the Jinan study. The original study lacked data and did not consider air pollution, smoking, eating habits,$$
\text { ect which may affect the temporal and spatial evol }
$$

\section{Conclusions}


As UHI keeps intensifying, the effect level and area on CVDs show an upward

401

402

403 trend and three evolution stages (concentric ring growth, axis expansion, and regional filling). The affected areas spread from the central urban area to suburbs, whereas more severely affected areas are mostly located in the central and southern areas.

The landscape pattern of the effect of UHI on CVDs reveals, in terms of quantity, a gradual fragmentation of the patches with the rise of patch quantity and density, and high-level patch plaque dominance. In terms of shape, the patches become irregular and space imbalanced; in terms of structure, the patch types of the entire landscape are more, yet weakly interconnected, whereas low-level areas are better interconnected in clusters.

UHI increases the environmental temperature during summer, and long-term exposure to high temperatures affects the functions of the human heart, thereby triggering CVDs and increasing the mortality rate during summer.

This study uses the landscape indices to assess the characteristics of the effect of UHI on CVDs, demonstrates the trend of spatio-temporal evolution of this effect, and provides theoretical evidence for early warning on CVDs.

\section{List of abbreviations}

AI, aggregation index; AREA_MN, mean patch area; CONTAG, contagion index; CVDs, cardiovascular diseases; ED, edge density; ICD-10, International Classification of Diseases, 10th revision; LSI, landscape shape index; LST, land surface temperature; NDVI, normalized difference vegetation index; NDWI, 
normalized difference water index; NSAT, near-surface air temperature; PD, patch density; SHAPE_AM, shape index; SHDI, Shannon diversity index; UHI, urban heat island

Ethics approval and consent to participate: Not applicable.

Consent for publication: Not applicable.

\section{Availability of data and materials:}

The dataset is available from the corresponding author upon request.

Competing interests: The authors declare that they have no competing interests.

\section{Funding:}

This research was funded by the National Natural Science Foundation of China projec t (grant numbers 31971717 and 31600571) and the Top-notch Academic Program s Project of Jiangsu (grant number PPZY2015A063).

\section{Authors' contributions:}

HHC performed the data analyses and developed the study protocol. DX contri buted significantly to analysis and refined the manuscript. YHL revised the ma nuscript. HC helped perform the analysis with constructive discussions. PZR pl ayed an important role in interpreting the results. LW performed the typesetting. All authors commented on the manuscript at various stages. All authors read and approved the final version of the paper.

\section{Acknowledgements:}


443 This study was supported by Professor Yun Yingxia.

444

445

446 


\section{References}

1. United Nations. $68 \%$ of the world population projected to live in urba n areas by 2050, says UN. 2018. Available from: https://www.un.org/de velopment/desa/en/news/population/2018-revision-of-world-urbanization-pro spects.html.

2. Baccini M, Biggeri A, Accetta G, Kosatsky T, Katsouyanni K, Analitis A, et al. Heat effects on mortality in 15 European cities. Epidemiolog y. 2008; 19:711-9.10.1097/EDE.0b013e318176bfcd.

3. World Health Organization. Cardiovascular diseases (CVDs). 2017. Avai lable from: https://www.who.int/news-room/fact-sheets/detail/cardiovascula r-diseases-(cvds).

4. Ostro BD, Roth LA, Green RS, Basu R. Estimating the mortality effec $\mathrm{t}$ of the July 2006 California heat wave. Environ Res. 2009; 109:614-9. http://dx.doi.org/10.1016/j.envres.2009.03.010.

5. Kenney WL, Craighead DH, Alexander LM. Heat waves aging and hu man cardiovascular health. Med Sci Sports Exerc. 2014; 46:1891-9. htt ps://doi.org/10.1249/MSS.0000000000000325.

6. Vandentorren S, Bretin P, Zeghnoun A, Mandereau-Bruno L, Croisier A, Cochet C, et al. August 2003 heat wave in France: Risk factors for d eath of elderly people living at home. Eur J Public Health. 2006; 16:5 83-91. https://doi.org/10.1093/eurpub/ck1063.

7. Silveira IH, Oliveira BFA, Cortes TR, Junger WL. The effect of ambie 
nt temperature on cardiovascular mortality in 27 Brazilian cities. Sci T otal Environ. 2019; 691:996-1004. https://doi.org/10.1016/j.scitotenv.2019. 06.493.

8. Williams S, Nitschke M, Sullivan T, Tucker GR, Weinstein P, Pisaniell o DL, et al. Heat and health in Adelaide, South Australia: Assessment of heat thresholds and temperature relationships. Sci Total Environ. 20 12; 414:126-33. https://doi.org/10.1016/j.scitotenv.2011.11.038.

9. Wu, C.G., Cui, H.L., Lin, Y.Y., Wang, Y.W., Gong, Y.X., Ma, X.Y., 20 
13. Tran PM, Waller L. Effects of landscape fragmentation and climate on lyme disease incidence in the Northeastern United States. Ecohealth. 2 013; 10:394-404. https://doi.org/10.1007/s10393-013-0890-y.

14. Li J, Xu X, Yang J, Liu Z, Xu L, Gao J, et al. Ambient high temper ature and mortality in Jinan, China: A study of heat thresholds and vul nerable populations. Environ Res. 2017; 156:657-64. http://dx.doi.org/10. 1016/j.envres.2017.04.020

15. Zanter K. LANDSAT 8 (L8) DATA USERS HANDBOOK Version 1.0 June 2015. United States Geol Surv. 2015; 1:1-106.

16. Li N, Xu YM, He M, Wu XH. Retrieval of Apparent Temperaturein B eijing Based on Remote Sensing. Ecol Env.2018;27:1113-1121. https://d oi.org/10.16258/j.cnki.1674-5906.2018.06.016(in Chinese).

17. Martin P, Baudouin Y, Gachon P. An alternative method to characterize the surface urban heat island. Int J Biometeorol. 2015; 59:849-61. htt ps://doi.org/10.1007/s00484-014-0902-9.

18. Qin Z, Li W, Xu B, Jia L. The estimation of land surface emissivity $\mathrm{f}$ or landsat TM6. Remote Sens L Resour. 2004;28-32. https://doi.org/10.3 969/j.issn.1001-070X.2004.03.007 (in Chinese).

19. Liang YQ, Hong $\mathrm{X}, \mathrm{Xu} \mathrm{F}$. Impacts of meteorological factors on death caused by cardiovascular disease in Nanjing City. Chinese J. Dis. Cont rol Prev. 2015; 19: 24-27. https://doi.org/10.16462/j.cnki.zhjbkz.2015.01. 001(in Chinese) 

emperature and mortality: An international study in four capital cities o f East Asia. Sci Total Environ. 2009; 408:390-6. http://dx.doi.org/10.10 16/j.scitotenv.2009.09.009

21. Kang N, Li Z, Luo L, Ni H, Wu Y. Meteorological Assessment of Ec ological Qualities and Bio-Meteorological Indicators in Ya'an. Plateau Mt Meteorol Res. 2010; 30:36-42. 10.3969/j.issn.1674-2184·2010.03.006 (in Chinese).

22. Wang Y, Shen Y. Shanghai summer temperature and humidity effect an d human comfort. J East China Norm Univ Sci. 1998;60-6. (in Chines e). 

ults: Effect Modification by Individual Characteristics. Sci Rep. 2016; 6: 1-9. http://dx.doi.org/10.1038/srep21003. $\mathrm{g}$ the impacts of ambient temperatures on cardiovascular mortality in $\mathrm{Y}$ inchuan: evidence from a northwestern city of China. Environ Sci Poll ut Res. Environmental Science and Pollution Research; 2018; 25:603643. https://doi.org/10.1007/s11356-017-0920-3.

28. Basu R, Ostro BD. A multicounty analysis identifying the populations vulnerable to mortality associated with high ambient temperature in $\mathrm{Cal}$ ifornia. Am J Epidemiol. 2008; 168:632-7. https://doi.org/10.1093/aje/k

29. Cheng X, Su H. Effects of climatic temperature stress on cardiovascula 2010; 21:164-7. https://doi.org/10.1016/j.ejim.2010.03.001.

30. Urban A, Davídkovová H, Kyselý J, Heat- and cold-stress effects on c ardiovascular mortality and morbidity among urban and rural population s in the Czech Republic. Int. J. Biometeorol. 2014; 58: 1057-1068. htt ps://doi.org/10.1007/s00484-013-0693-4.

31. Li G, Zhou M, Cai Y, Zhang Y, Pan X. Does temperature enhance ac ute mortality effects of ambient particle pollution in Tianjin City, Chin a. Sci Total Environ. 2011; 409:1811-7. http://dx.doi.org/10.1016/j.scitot 
env.2011.02.005.

32. Dong J, Liu X, Zhang B, Wang J, Shang K. Meta-analysis of associati on between short-term ozone exposure and population mortality in Chin a. Acta Sci Circumstantiae. 2016; 36:1477-85. https://doi.org/10.13671/j. hjkxxb.2015.0555 (in Chinese).

33. Yang H, Xi Z, Liu X, Chu N. Research Progress in Effects of Ozone on Cardiovascular System. 2018;2-5. https://doi.org/10.13704/j.cnki.jyyx. 2018.02.034(in Chinese).

34. Yang C, Meng X, Chen R, Cai J, Zhao Z, Wan Y, et al. Long-term v ariations in the association between ambient temperature and daily card iovascular mortality in Shanghai, China. Sci Total Environ. 2015; 538:5 24-30. http://dx.doi.org/10.1016/j.scitotenv.2015.08.097.

35. Baaghideh M, Mayvaneh F. Climate Change and Simulation of Cardiov ascular Disease Mortality: A Case Study of Mashhad, Iran. Iran J Publ ic Health. 2017; 46:396-407.

36. Zhang S, Zhang X, Tian Y, Wang B. Effect and its Mechanism of Art ificial Heat Wave on Coronary Heart Diseases. Meteorol Mon. 2015; 4 1:761-70. 10. 7519/j.issn.1000-0526.2015.06.011(in Chinese).

37. Xie GD, Zhang B, Lu CX, Xiao Y, Liu CL, Zhang B, et al. Rapid expansion of the metropolitan areas and impacts of resources and the environment. Resour. Sci. 2015; 37:1108-1114(in Chinese). 


\section{Figures}

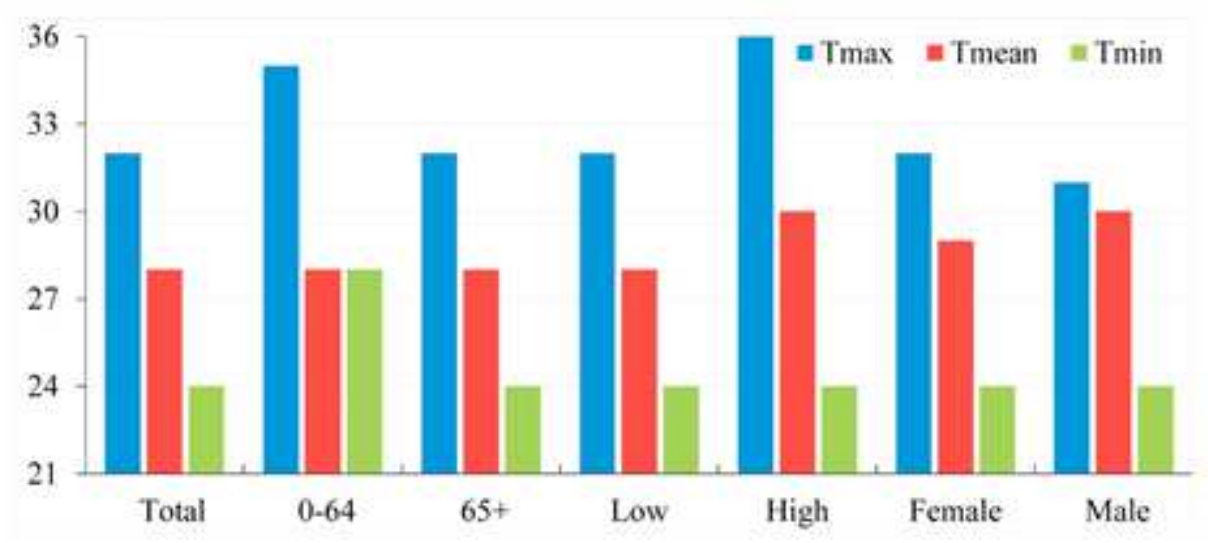

Figure 1

Heat thresholds of Tmax/Tmean/Tmin [14]

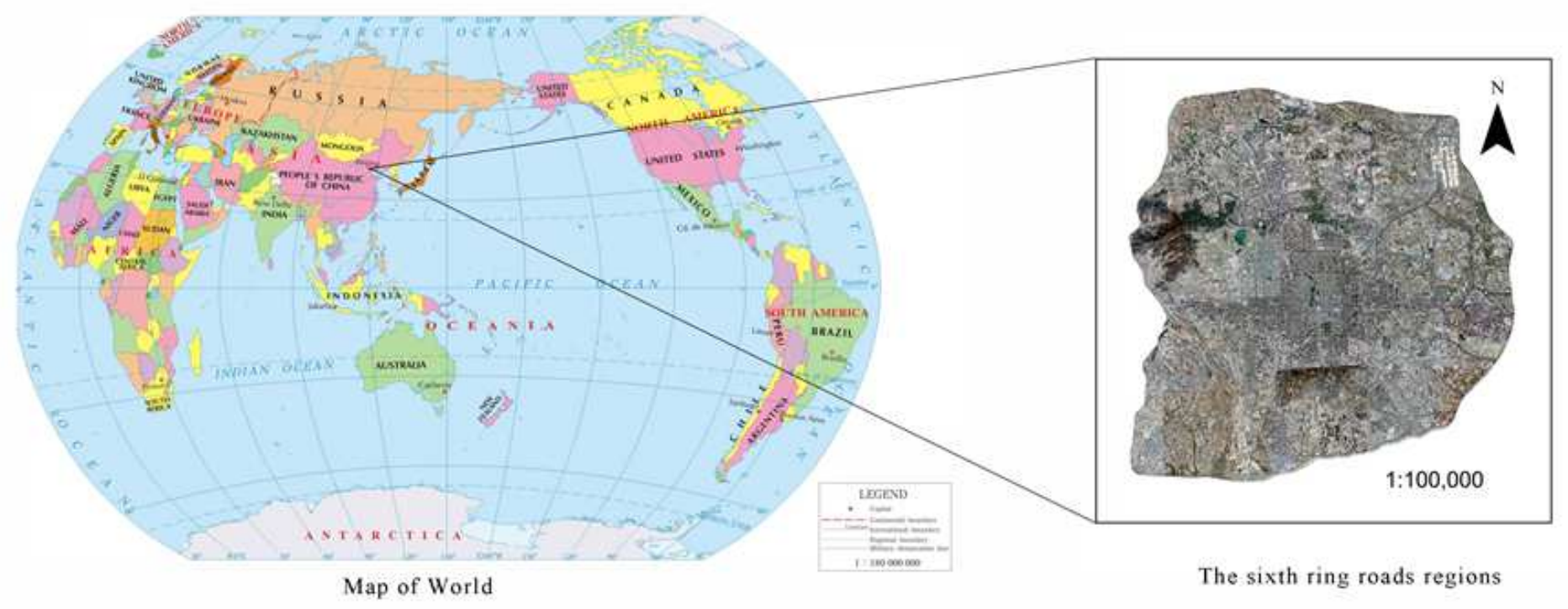

Figure 2

Outline of the study area Note: The designations employed and the presentation of the material on this map do not imply the expression of any opinion whatsoever on the part of Research Square concerning the legal status of any country, territory, city or area or of its authorities, or concerning the delimitation of its frontiers or boundaries. This map has been provided by the authors. 


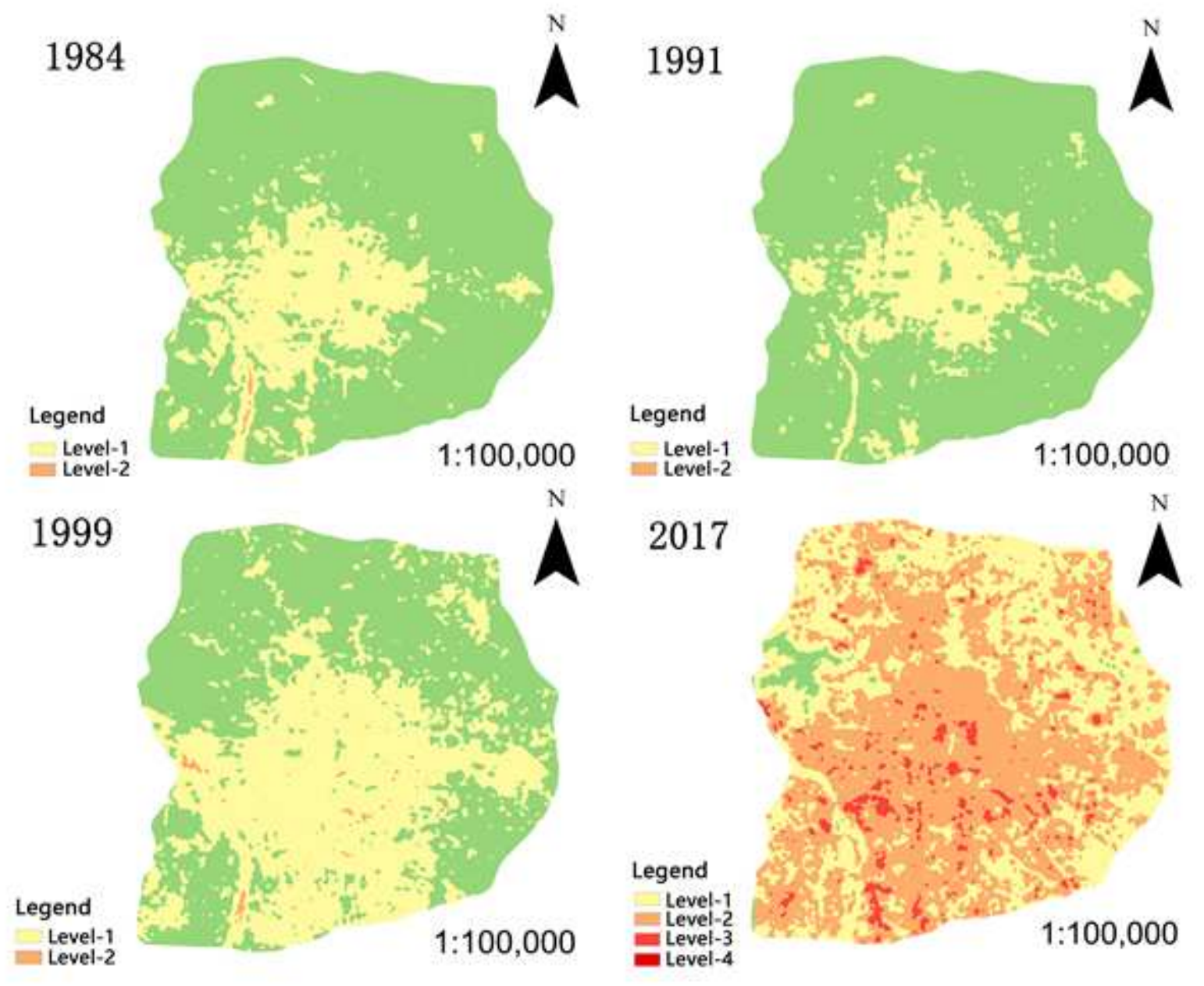

Figure 3

Distribution of affected areas during 1984-2017

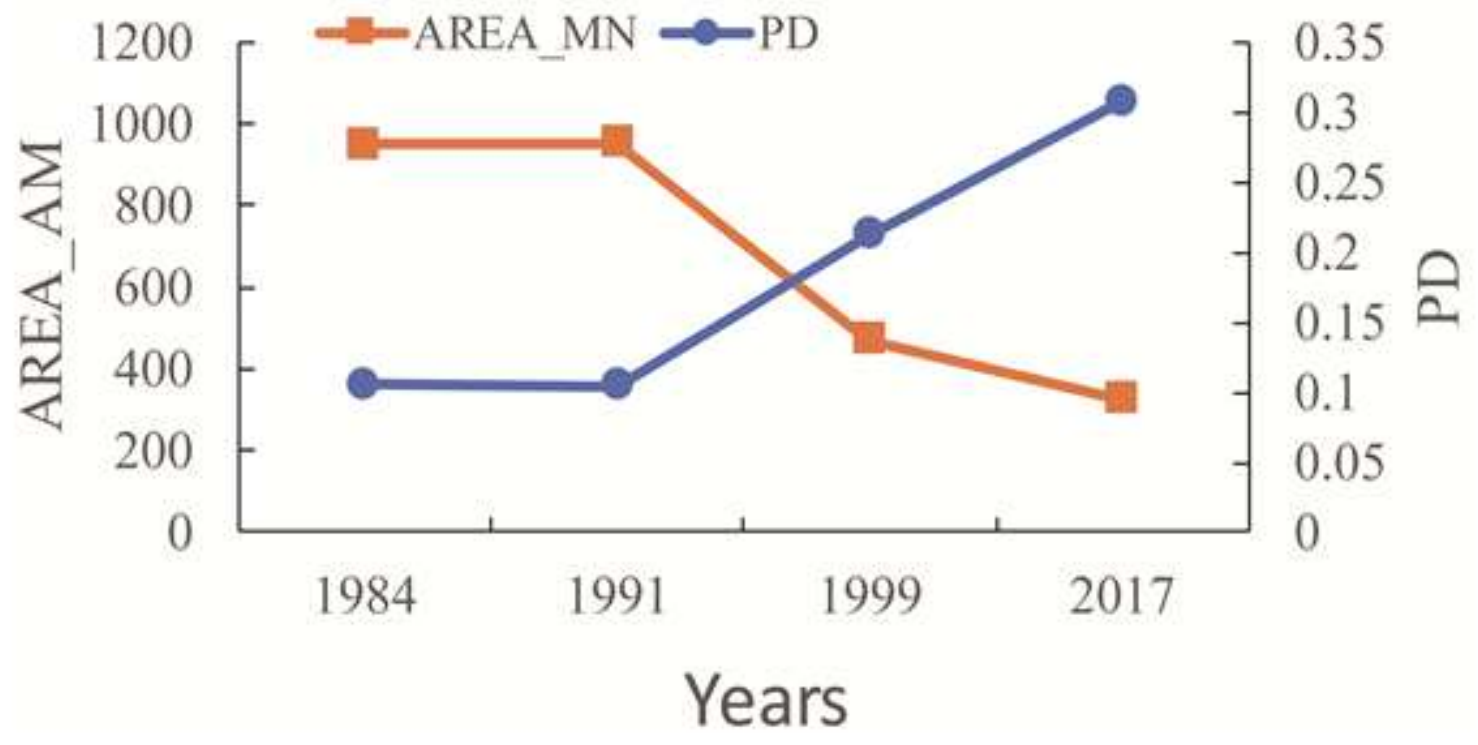

Figure 4 
Changes in PD and AREA_MN during 1984-2017

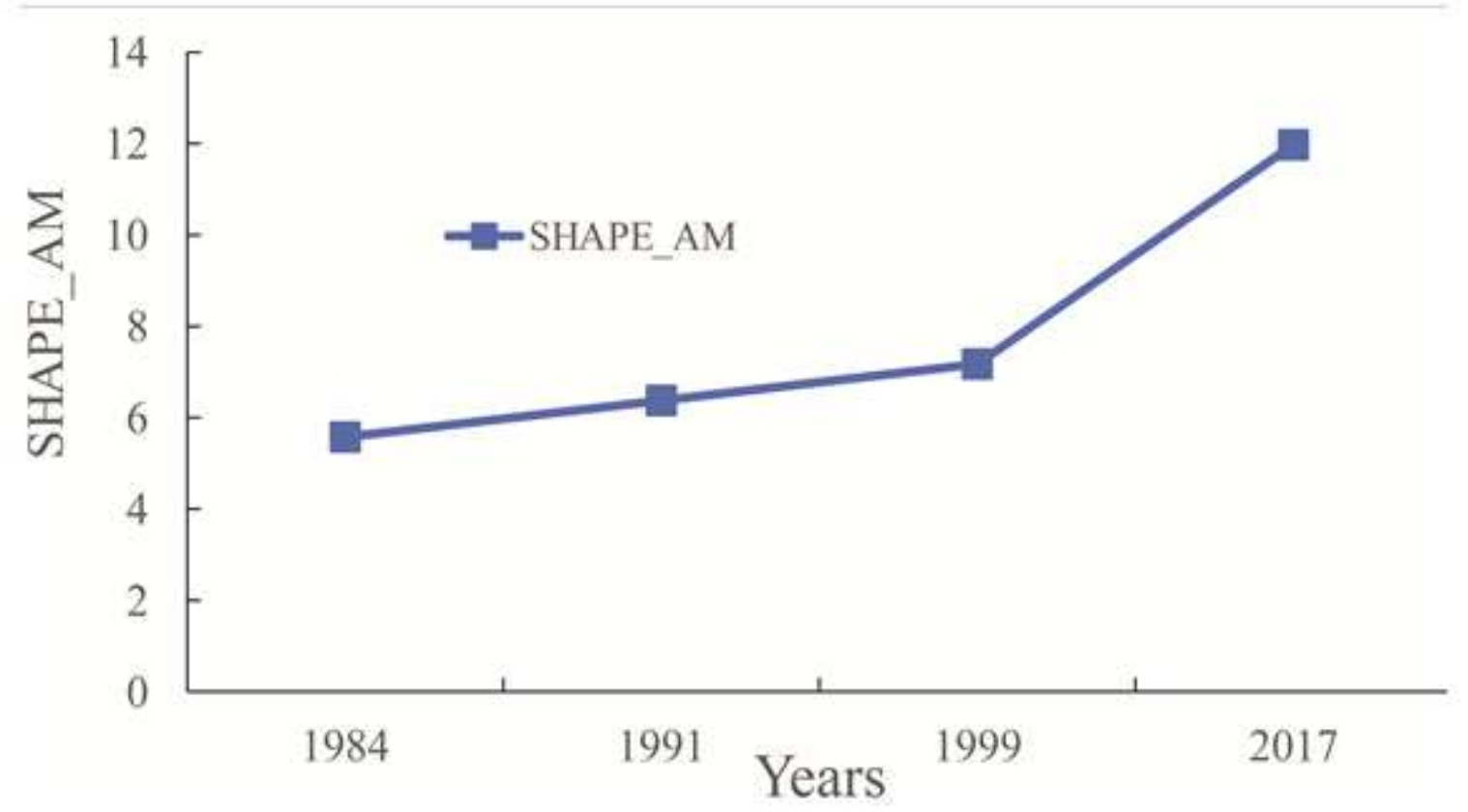

Figure 5

Changes in SHAPE_AM during 1984-2017
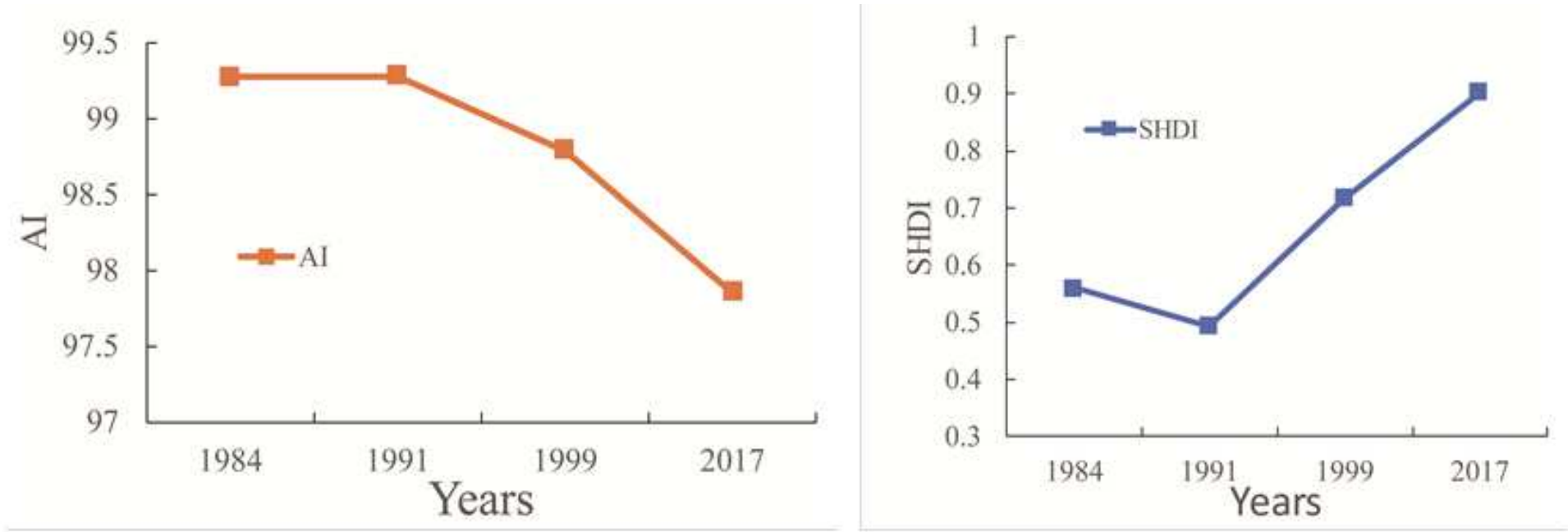

Figure 6

Changes in Al and SHDI during 1984-2017 

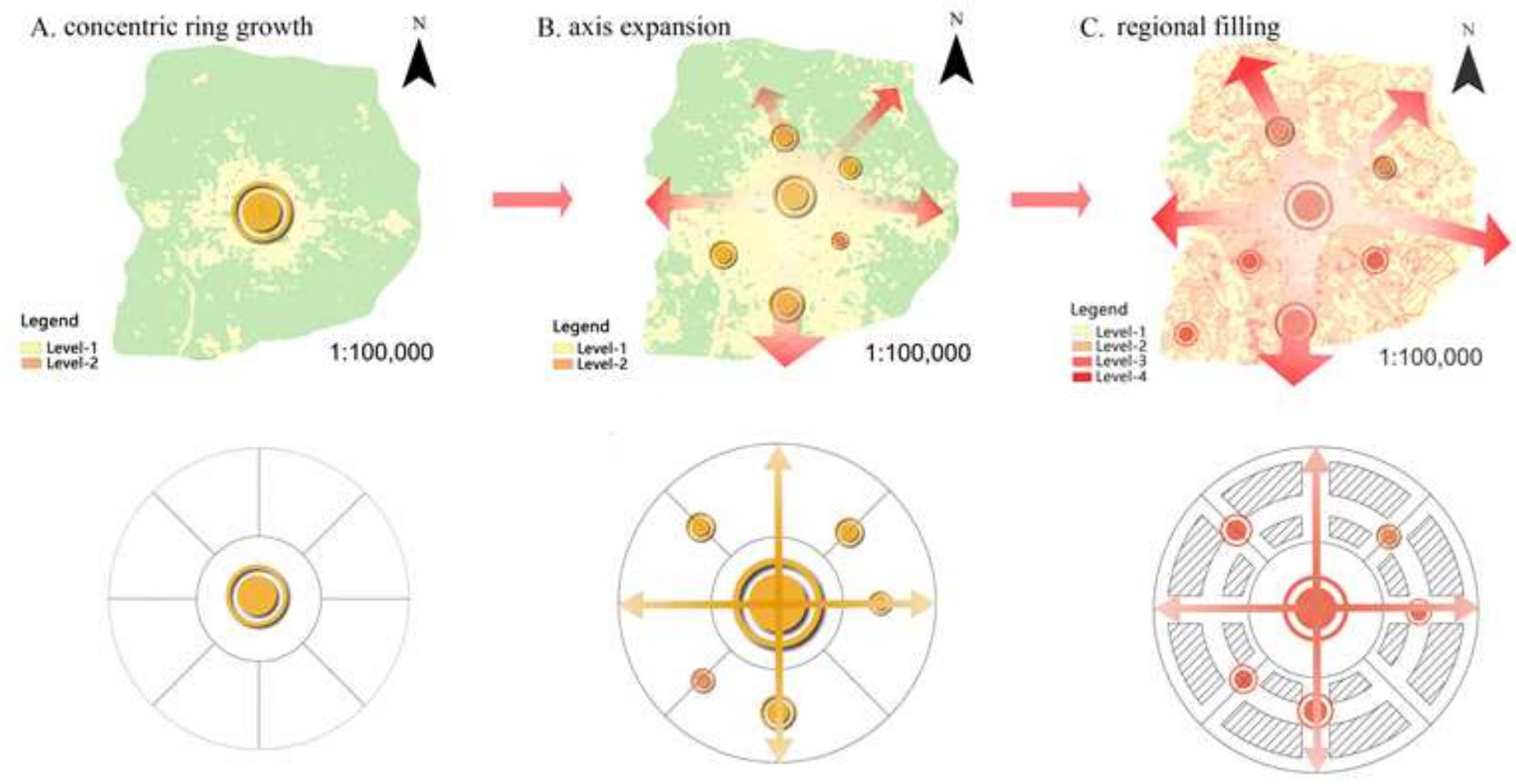

Figure 7

Stages of form evolution of UHI on CVDs 